\section{ULTRASONOGRAPHY: changes in \\ submission and publication patterns \\ 1 year after being listed in SCIE}

JEONG-SIK YU

Editor-in-Chief

ULTRASONOGRAPHY

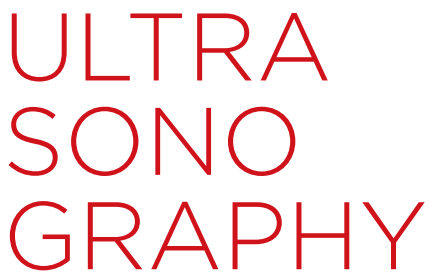

\section{EDITORIAL}

https://doi.org/10.14366/usg.20184 pISSN: 2288-5919 • elSSN: 2288-5943

Ultrasonography 2021;40:1-2

Received: November 20, 2020

Revised: November 20, 2020

Accepted: November 20, 2020 quintupled, with a particularly notable increase in submissions of domestic original articles (Fig. 1).

In 2014, the editorial system was changed to English-only and global-standard open access was introduced; since then, Ultrasonography has been listed in PubMed Central, Scopus, and Web of Science, all of which furnish evidence of the success of the journal's internationalization [2]. In this situation, the remarkable increase in domestic submissions may seem ironic. However, this trend can be interpreted as indicating that excellent domestic research that had been published overseas when our journal was limited to the status of a domestic journal is now returning, in line with the advanced international status of the journal. Of course, international submissions have also increased, but the rate of increase has been relatively low, and it is questionable whether the quality of submitted papers has improved. In addition, as the total number of submitted papers has increased, the review process has become stricter to resolve the gap between the number of submissions and the number of accepted papers. Naturally, the final acceptance rate has decreased by about $50 \%$ compared to the period 1 year earlier. Nevertheless, in order to process the gradually increasing list of "ahead-ofprint" articles on the journal homepage (https://e-ultrasonography.org), we will need to increase the number of articles in upcoming issues. Starting in 2021, each issue will contain at least 15 reviews and original articles.

The first issue of 2021 contains a total of six reviews and nine original articles. As has been noted, increasing the total number of publications tends to reduce the journal's impact factor in the short term $[2,3]$. In this regard, we will need to keep an eye on current hot topics so that our journal will have a wider readership and receive more citations [3]. To this end, Professor Seong Ho Park, an expert in artificial intelligence, was invited to serve as a guest editor, and a special feature on artificial intelligence in the field of clinical ultrasonography, which is currently a highly relevant topic, was

Jeong-Sik Yu, MD

Department of Radiology, Gangnam Severance Hospital, Yonsei University College of Medicine, 211 Eonju-ro, Gangnam-gu, Seoul 06273, Korea Tel. +82-2-2019-3510, Fax. +82-2-3462-5472, E-mail: yjsrad97@yuhs.ac
This is an Open Access article distributed under the terms of the Creative Commons Attribution NonCommercial License (http://creativecommons.org/ licenses/by-nc/4.0/) which permits unrestricted noncommercial use, distribution, and reproduction in any medium, provided the original work is properly cited.

Copyright @ 2021 Korean Society of Ultrasound in Medicine (KSUM)

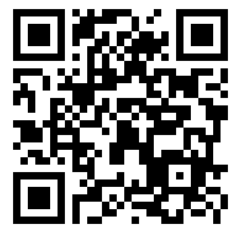

How to cite this article:

Yu JS. ULTRASONOGRAPHY: changes in submission and publication patterns 1 year after being listed in SCIE. Ultrasonography. 2021 Jan;40(1):1-2. 


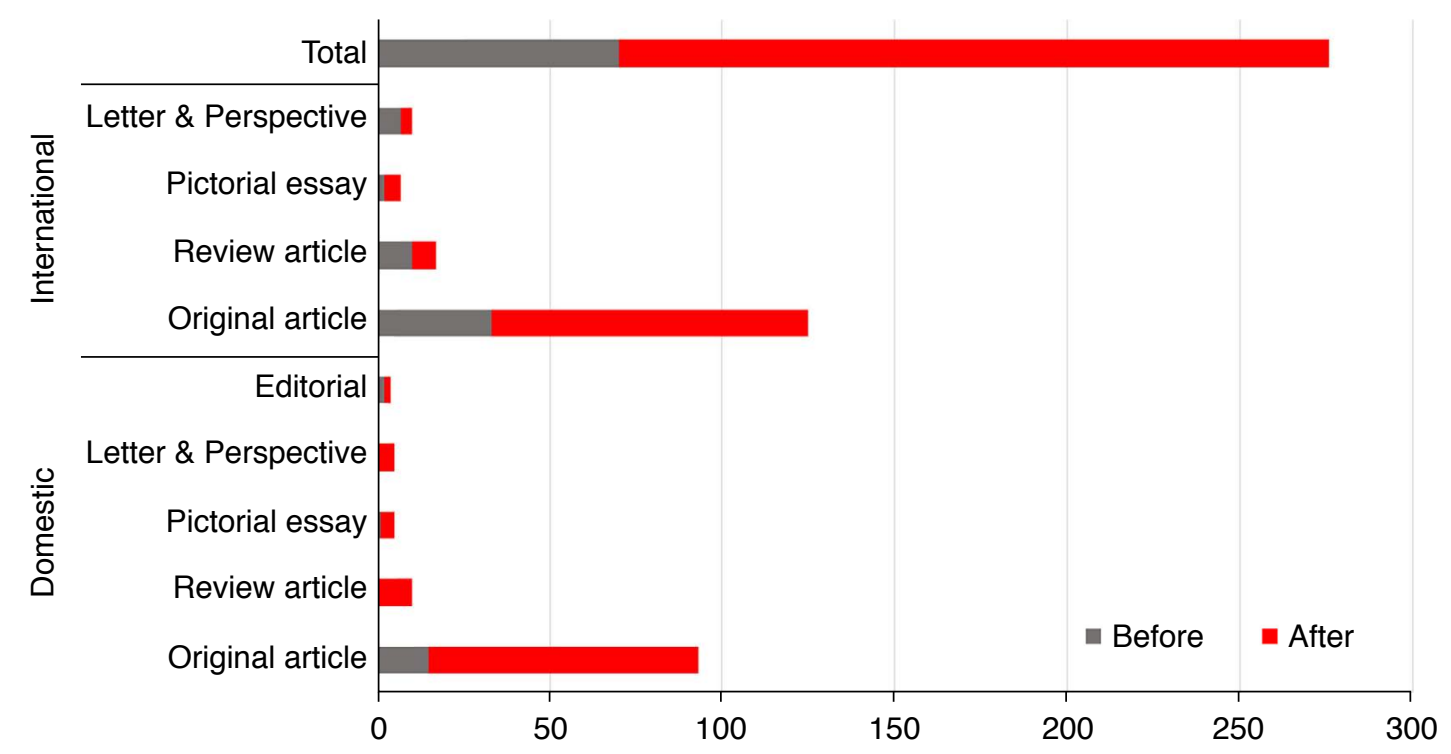

Fig. 1. Changes in the number and pattern of annual submissions to Ultrasonography after being indexed in SCIE. International submissions doubled (from 52 to 107) and domestic submissions quintupled (from 18 to 99); the increase in submissions of domestic original articles was particularly noteworthy (from 15 to 78 ).

prepared for the first and second issues of 2021 [4]. I believe that this special feature will provide a comprehensive overview of the technical aspects of the introduction of artificial intelligence for ultrasonography, the status and directions of development of the clinical applications of artificial intelligence, and its limitations and difficulties. I hope readers will enjoy this informative content.

ORCID: Jeong-Sik Yu: https://orcid.org/0000-0002-8171-5838

\section{References}

1. YU JS. ULTRASONOGRAPHY is now in SCIE. Ultrasonography 2019;38:277.

2. Huh S. Position of Ultrasonography in the scholarly journal network based on bibliometrics and developmental strategies for it to become a top-tier journal. Ultrasonography 2020;39:238-246.

3. Yu JS. ULTRASONOGRAPHY: coping with changes and setting new directions after being listed in SCIE. Ultrasonography 2020;39:1-2.

4. Park SH. Artificial intelligence for ultrasonography: unique opportunities and challenges. Ultrasonography 2021;40:3-6. 